\title{
Produktionsintegrierte Wendekammerstrahlanlagen
}

\section{Zylinderköpfe partiell strahlen}

\author{
Bei einem süddeutschen Automobilhersteller ermöglichen zwei kompakte, in bestehende \\ Fertigungslinien integrierte Wendekammerstrahlanlagen das partielle Strahlen von Zylinderköpfen.
}

W enn die Zylinderköpfe aus der ersten mechanischen Bearbeitung kommen, sind sie mit Flittergraten und teilweise noch mit Restsand aus dem Gießprozess verunreinigt. Um beides zu entfernen, integrierte der Automobilhersteller zwei identische Strahlanlagen in bestehende Fertigungslinien. Darin bestand auch eine der ersten Anforderungen an den Strahltechnikhersteller, dessen Anlagen nur eine definierte Aufstellfläche beanspruchen durften. Ein weiteres Kriterium war der zu strahlende Bereich. Lediglich die Brennkammerseite sollte bearbeitet werden, wobei drei Bohrungen ausgespart werden mussten und ein vorhandener Matrix-Code nicht beschädigt werden durfte.

Die Entscheidung fiel auf die kompakten Wendekammer-Strahlsysteme RWK 6/12-2 von Rösler mit einem Werkstück-Hüllkreis von 600 $\mathrm{mm}$ und einer Höhe von $1200 \mathrm{~mm}$. Jede Anlage verfügt über zwei Kammern, so dass die Be- und Entladung parallel zum Strahlprozess erfolgen kann. Für die erforderliche Strahlintensität sorgen jeweils zwei Turbinen (Typ Hurricane H 32) mit 7,5 kW Antriebsleistung.

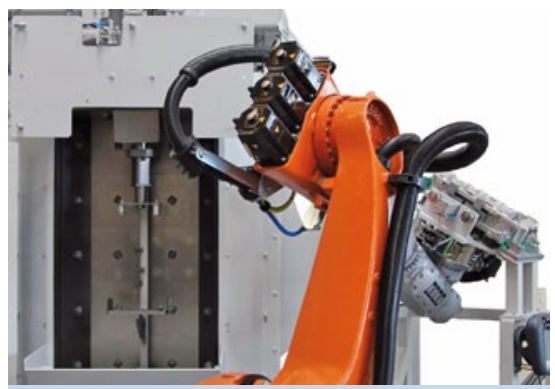

Das für den Be- und Entladeroboter speziell entwickelte Greifersystem kann die Zylinderköpfe an zwei unterschiedlichen Positionen fassen

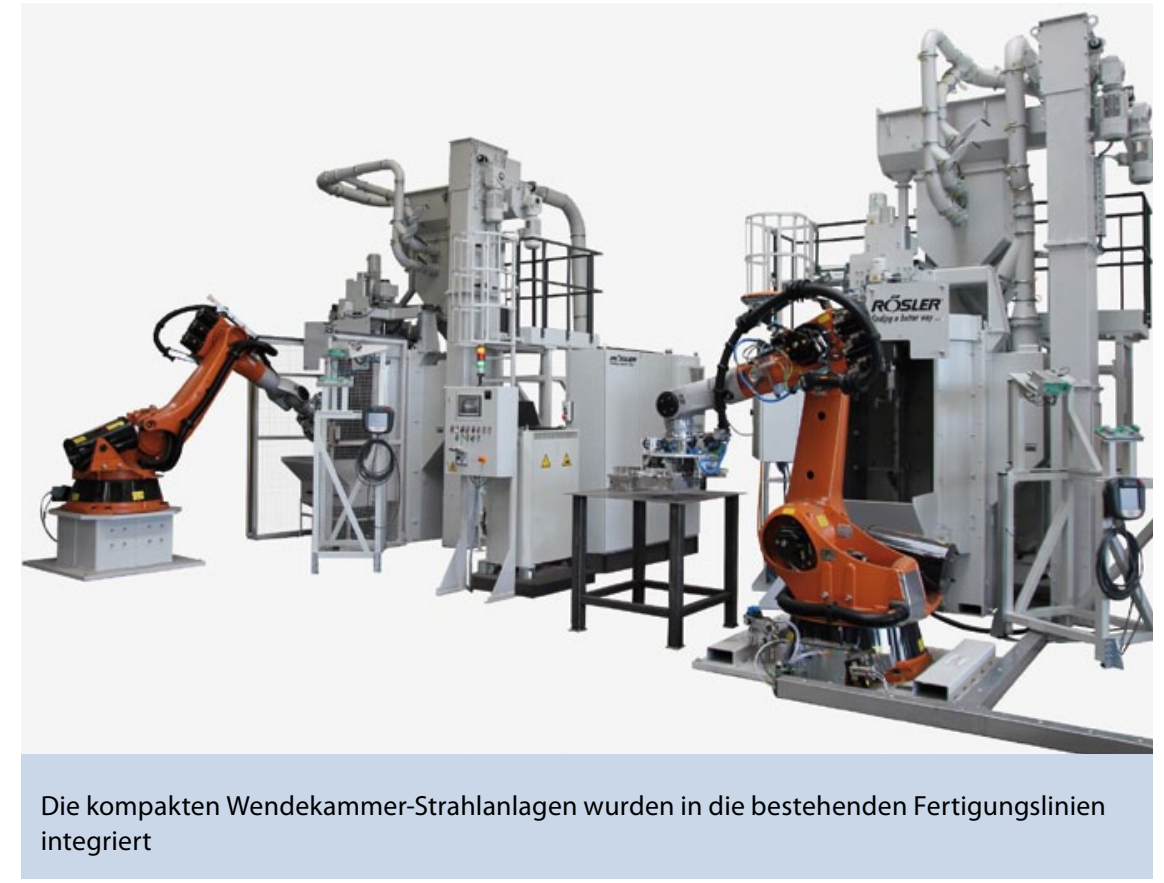

Positionieren, abdecken und strahlen in 60 Sekunden

Die Teile werden auf Rollenbahnen zu den Strahlanlagen transportiert. Dort nimmt sie ein Roboter in Empfang, für den Rösler ein spezielles Greifersystem entwickelte. Es ermöglicht, die Zylinderköpfe in unterschiedlichen Bereichen zu fassen. Zuerst greift das System den Zylinderkopf an einem Bügel und transportiert ihn zu einer Umgreifstation. Mit dem zweiten Griff wird das Bauteil auf der anwendungsspezifisch gestalteten Werkstückaufnahme abgesetzt. Der zu strahlende Bereich befindet sich oben, die drei Bohrungen und der Matrix-Code werden automatisch durch Pins beziehungsweise eine Platte abgedeckt.

Nachdem der Zylinderkopf auf der Werkstückaufnahme befestigt ist, taktet es die Anlage in die Strahlkammer. Diese ist aus Manganstahl gefer- tigt und mit zusätzlichen auswechselbaren Platten ausgestattet. Während des Strahlprozesses pendelt die Werkstückaufnahme. Durch diese Bewegung werden nur die zu strahlenden Bereiche der Zylinderköpfe bearbeitet. Nach dem Strahlvorgang taktet die Anlage zurück in den Be- und Entladebereich, wo der Roboter im Zylinderkopf befindliches Strahlmittel durch eine spezielle Bewegung entleert und ihn dann zurück auf die Rollenbahn legt. Inklusive Be- und Entladen, Abdecken und Strahlen beträgt die Taktzeit 60 Sekunden. Um zu verhindern, dass entfernter Sand in den Strahlmittelkreislauf gelangt, sind die Anlagen mit Abscheidesystemen für die Trennung von Sand/Metallspänen und Strahlmittel ausgestattet. Doris Schulz

\section{Kontakt::}

Rösler Oberflächentechnik GmbH, Untermerzbach,

Tel.09533 9240, info@rosler.com,

www.rosler.com 